\title{
Different Mechanism Involvement in the Formation of Colorectal Cancer; Mega Review
}

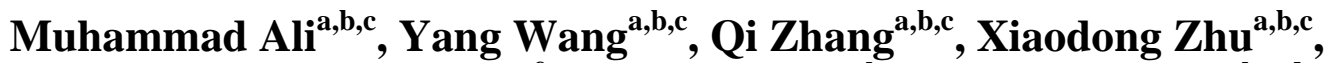 \\ Abass Mahamoud Ahmed ${ }^{\text {c,f }}$, Mingrui Jiang ${ }^{a, b, c}$, Daorong Wang ${ }^{a, b, c, d, e}$ \\ aNorthern Jiangsu People's Hospital, Yangzhou 225001, China. \\ ${ }^{\mathrm{b}}$ General Surgery Institute of Yangzhou, Yangzhou University, Yangzhou 225001, China. \\ ${ }^{c}$ Medical College of Yangzhou University, Yangzhou 225001, China. \\ ${ }^{\mathrm{d}}$ Dalian Medical University, Dalian 116044, China. \\ ${ }^{\mathrm{e}}$ Department of Physiology, Nanjing Medical University, Nanjing 211166, China. \\ fYangzhou first People's Hospital, Yangzhou University Affiliated Hospital. Yangzhou 225001, China.
}

Corresponding Author: Daorong Wang

\begin{abstract}
Colorectal cancer was infrequently diagnosed several decades ago. Nowadays, it is the world's fourth most deadly cancer with almost 900,000 deaths annually. Colorectal cancer had a low incidence several decades ago. However, it has become predominant cancer and now accounts for approximately $10 \%$ of cancer-related mortality in western countries. The 'rise' of colorectal cancer in developed countries can be attributed to the increasingly aging population, unfavorable modern dietary habits and an increase in risk factors such as smoking, low physical exercise and obesity. New treatments for primary and metastatic colorectal cancer have emerged, providing additional options for patients; these treatments include laparoscopic surgery for primary disease, more aggressive resection of metastatic disease (such as liver and pulmonary metastases), radiotherapy for rectal cancer and neoadjuvant and palliative chemotherapies. However, these new treatment options have had a limited impact on cure rates and long-term survival.
\end{abstract}

Keywords: Colorectal cancer, Tumor marker, Hereditary colorectal cancer, Mediterranean diet.

\section{INTRODUCTION}

Colorectal cancer (CRC) is the most ubiquitous cancer and one of the foremost causes of cancer worldwide [1]. Over the previous 20 years, the clinical consequence for these patients has greatly enhanced because of the development in accessible systemic therapies and ablative procedures, additionally to upgraded diagnosis and appointment for surgery [2]. Historically, journals have distinct CRCs within three sections of the gut: proximal colon, distal colon and rectum [3-5]. Right-sided colon carcinomas (RCCs) are positioned within the colon derived from the embryonic midgut, which covers the proximal twothirds of the transverse colon, ascending colon and caecum (Fig. 1). Left-sided colon carcinomas (LCCs) positioned within the colon derived from the embryonic hindgut, which consists of the distal third of the transverse colon, splenic flexure, descending colon, sigmoid colon and rectum. With this description, CRC with LCC has no less than $63 \%$ of patients [6].

\section{Embryology}

The right (Midgut) and the left (Hindgut) side of the gut develop from the endoderm by gastrulation and distribute the guts to the cloacal membrane along with the embryo. In the midgut, the whole of the small bowel, the caecum, the appendix, the ascending colon and the proximal two-thirds of the transverse colon separates into a duodenum distal to the ampulla [7]. 
The hindgut gives rise to the distal third of the transverse colon, the splenic flexure, the descending colon and sigmoid rectum, and the upper part of the anal canal [8]. The most distal part of the hindgut enters the cloaca's posterior region, known as the primitive anorectal canal, from which the anal region derives.

Because both the right and left sides of the colon are derived from endoderm [7], embryology does not appear to be the primary reason for the differences in CRC prognosis reported. As mentioned later in this article [9], distinct gene expression variances representing midgut and hindgut changes have been identified between the right and left sides of the normal colon.

\section{Microbiome interaction with CRC}

It is hypothesized that the microbiome plays a key role in CRC formation. Depending on the primary location of the tumor, bacterial phylotype may differ. The prevalence of RCCs is relatively more than that of LCC with Fusobacterium, Escherichia-Shigella and Leptotrichia than that of Prevotella, Pyramid-bacterium, Seleneomonas and Peptostreptococcus, compared to RCC [10].

A significantly higher incidence of Escherichia coli phylogroup B2 has been detected in mucosal biopsies from patients with RCC compared to those with LCC [11], and a higher risk of Helicobacter pylori infection was reported in patients with LCC compared to those with RCC [12].

\section{Role of biofilms}

Dense bacterial aggregates or biofilms are positioned within the normal gut and are associated to decreased activation and increased epithelial cell proliferation of e-cadherin, enhanced transducer-size (IL-6) and a transcriptionsignal activator, STAT3. Biofilms can invade and pathogenic mucus layer of the colon in direct touch with the mucosal epithelial cells. The majority of RCCs, however only a small percentage of the
LCC [13] were found to have invasive polymicrobial biofilms.

\section{Role of pathogen in CRC}

Both mechanisms have been postulated. Prevotella, Pyramido-bacterium, Selenomonas and Peptostreptococcus were identified in relatively higher abundance in proximal tumors compared with distal tumors. Conversely, Fusobacterium, Escherichia-Shigella and Leptotrichia were relatively abundant remains uncertain whether the changed mucosa following the development of CRC attracts different bacteria or if different bacteria have an ability to destroy the mucosa, which then leads to CRC.nt in distal colorectal tumours compared with proximal tumours [10]. Recently published data show that CRCassociated bacterial clusters are differentially correlated with mucosal gene expression profiles. Some clusters are partly associated with the expression of proinflammatory genes in the mucosa, which may result in CRC in the future [14].

\section{Role of primary tumour}

Patients with RCC are more likely than those with LCC to be female, and their median age at diagnosis is higher than that of patients with LCC [6]. RCCs are more likely to have high-grade histology and a more advanced tumour stage at initial presentation compared with LCC [6]. LCC is linked to a low-fiber diet, smoking, and excessive alcohol consumption [15]. The spread of metastatic disease varies depending on the primary location of the CRC. RCC is more likely to spread to the peritoneum, while LCC is more likely to spread to the liver and lung [16].

\section{Role of Molecular and Chromosomal difference in CRC}

A number of chromosomal and molecular differences have been reported between RCC and LCC. In about $75 \%$ of LCC and $30 \%$ of RCC Instability of chromosomes has been detected [15]. In comparison with LCC, hypermutation is higher in RCC [16]. RCC have been shown 
to be associated with an increase in RAS and phosphoinositide 3-kinase pathway mutations [17], $\mathrm{CpG}$ island methylator phenotype (CIMP)-high and microsatellite instability-high subtypes (Fig. 2A) and BRAF mutations (Fig. 2B) [16,18]. The rate of mutations from KRAS/BRAF has been observed to gradually decrease to sigmoid colon from caecum (Fig. 2B) [11]. A higher expression of TGF $\beta$ R2 mutations also occurs within the RCC compared with the LCC [19].

In LCC mutations are more frequent compared with RCC in the APC, KRAS, SMAD4, and TP53 genes [20]. In addition to greater chromosomal instability, LCC has been linked to higher overexpression of the epidermal growth factor receptor (EGFR) ligands, epiregulin (EREG) and amphiregulin (AREG), as well as EGFR and human epidermal growth factor receptor 2 amplification (HER2) [16,21-22\}]. High AREG expression is inversely associated with BRAF mutation and CIMP-high status [21]. Hypermethylation and suppression of EREG and AREG expressions have been demonstrated to be strongly associated with RCC and CIMP-high status [23].

The predominant angiogenic factor, vascular endothelial growth factor (VEGF1), plays a key role in the progression of CRC. VEGF-1 expression has been found to be substantially higher in LCC than in RCC [24]. Similarly, LCC had higher levels of cyclooxygenase-2 (COX-2), which also plays a role in angiogenesis, when compared to RCC [25].

\section{Causes of CRC}

Dietary habits are the primary risk factors for colorectal cancer, however, obesity and physical inactivity are also significant risk factors. Other conditions that predispose to colorectal cancer include inflammatory bowel disease (IBD) (ulcerative colitis or Crohn's disease), cigarette smoking, and $5-10 \%$ of cases of hereditary diseases (e.g., pre-cancerous conditions) such as Lynch syndrome (also known as hereditary nonpolyposis colorectal cancer) and familial adenomatous polyposis (FAP) or, less frequently, are associated with MY (PJS). About $20 \%$ of patients with colorectal cancer mainly have these disorders when the disease is detected in younger $(<45)$ and in more than a first-grade relative $(1,5)$ The chance of getting colorectal cancer in patients with polyps $>1$ $\mathrm{cm}$ and $>2$ polyps or with dysplasia is greater [26]. Increase risk has also been reported in patients with Diabetes Mellitus, but the proper link is not clear that it is simply environmental (i.e., due to the impact of joint risk factors, such as physical inactivity and obesity) or due to disease pathogenicity. Reliable evidence gathered on over 2.1 million subjects shows that colorectal cancer mortality can be reduced by $\sim 20 \%$ with the use of the Mediterranean diet [27].

Another recent meta-analysis concluded that saturated or animal fats and cholesterol, red and processed meat, preserved and spicy foods are associated with an increased risk of colorectal cancer in Asia, whereas dairy foods, calcium, vegetables and fruit, as well as lycophene, selenium, and carotenoids may be protective. Primary prevention techniques such as increased physical activity and dietary changes, as well as secondary prevention strategies such as screening, have been used to lower colorectal cancer incidence and death [28-33].

\section{Associated factor of CRC}

Modifiable risk factors for $\mathrm{CRC}$ include smoking, alcohol consumption, obesity, and consumption of processed and red meat. Modifiable factors linked to a lower risk of colorectal cancer include improved physical activity, nonsteroidal anti-inflammatory drugs, postmenopausal hormone therapy, and vegetable and fruit intakes. Studies correlating fruit and vegetable consumption to a lower risk of colorectal cancer have been found to be unreliable. [34].

Age, IBD, and a family history of colorectal cancer are non-modifiable factors 
with a significant association. Screening methods begin at the age of 50 have been found to lower CRC incidence and mortality by detecting and removing precancerous polyps early. [35].

\section{Hereditary CRC}

Genetic predisposition is important in the etiology of $\mathrm{HCC}$, as well as in determining the clinical course and prognosis of the disease, particularly in the young population (30 years) [36]. Predisposing factors for HCRC include Lynch syndrome (LS), familial adenomatous polyposis (FAP), MUTYHassociated polyposis (MAP), serrated polyposis syndrome, juvenile polyposis syndrome, Peutz-Jeghers syndrome, and Cronkhite-Canada syndrome [37]. The most common causes of HCRC are LS and FAP, which account for $3 \%$ and $1 \%$ of all HCRC cases, respectively. [38].

\section{Lynch syndrome}

Lynch syndrome is an inherited disorder that has been linked to an increased risk of many types of cancer, including colon cancer. It is, in fact, the most common hereditary condition associated with an increased risk of getting colorectal cancer. [38]. About 3\% of all cases of colorectal cancer have LS and could be life-long at risk for getting colorectal cancer, depending on the type of mutation in issue, between $20 \%$ and $80 \%$, with $54 \%$ cumulative risk. [39]. LS is inherited from an autosomal predominant pattern and the genetic alterations revolve around MMR genes including (MLH1), (MSH2) and (PMS2) which thus prevent the correct repair of the DNA replication defects [40].

\section{Familial adenomatous polyposis}

Familial adenomatous polyposis is an autosomal dominant illness that affects both men and women equally. It is predicted that $1 / 14000-1 / 8300$ live births are affected. This condition is caused by a mutation in the Adenomatous polyposis coli (APC) gene, which results in an altered tumor suppressor APC gene, resulting in uncontrolled proliferation of cells in the colon, resulting in hundreds to thousands of adenomatous polyps (Fig. 2). FAP is the most common cause of adenomatous polyps in the pediatric population: $50 \%$ of people would develop adenomas by the age of 15 years, which increases to $95 \%$ by the age of 35 . Patients typically develop $>100$ colonic polyps, among extra-colonic manifestations, such as duodenal and gastric polyps, soft tissue, and bone and skull tumors. If left untreated, $100 \%$ of FAP patients will develop CRC by the fourth or fifth decade of life [41].

The adenomatous colorectal polyps are different in size, but usually have 1-2 $\mathrm{mm}$ in diameter, with pedunculated variants of up to $1 \mathrm{~cm}$. FAP may occur in two forms: diffuse in the development of hundreds of polyps, or profuse in the development of thousands of polyps. Signs and symptoms are rectal bleeding, anemia, increased frequency of stools and abdominal pain but are not limited to them.

\section{Diabetes with CRC}

Justin Y. Jeon evaluate the impact of diabetes on outcomes in colorectal cancer patients and to examine whether this association varies by the location of the tumor and found significantly reduced overall and disease-free survival only in colon cancer but not in rectal patients with DM [43].

\section{Post-menopausal Obesity co-relation with CRC}

The prevalence of obesity is on the rise around the world and obesity is a major health issue, including in the Asian countries where the average BMI and obesity prevalence were once lower than in western countries. Obesity in postmenopausal Korean women was associated with an overall higher risk of cancer, comparable with findings from Western population studies. In postmenopausal females, an active effort is needed for obesity prevention to decrease the risk of cancer in particularly colon, breast, corpus uterus and kidney cancer is 
given the increasing prevalence of obesity in postmenopausal females [44].

\section{Circulating Concentrations of Inflammatory Biomarkers and Risk of CRC}

\section{C-reactive protein (CRP)}

C-reactive protein (CRP) is a sensitive, but non-specific, systemic biomarker of inflammation, produced predominantly in the liver in response to cytokines released by phagocytes after infection, trauma, surgery [45]. TCRP concentrations in the blood are low in healthy people, usually less than $1 \mathrm{mg} / \mathrm{L}$, but they rise during acute infection, reaching levels well above $10 \mathrm{mg} / \mathrm{L}$. CRP has a half-life of 19 hours [46].

\section{Interleukin-6 (IL-6)}

Interleukin-6 (IL-6) is a multifunctional cytokine released by hematopoietic and not bloody cells[47], which works on a transmembranous cytokine type 1 receptor or binds to a soluble IL-6 receptor (sIL6R). IL-6 increases the levels of many acute-phase proteins, including CRP, fibrinogen, 1antitrypsin, and serum amyloid A. [48]. There are considerable mechanistic indications that IL-6 is involved in the development of the CRC. In vivo experiments on wild-type mice revealed that IL-6 is drastically increased in the colonic tumor environment and that the growth of colon tumors was inhibited when the mice were given anti-IL6R antibodies. [49]. However, epidemiological research has been limited with only six prospective studies available [50-54], relating to the combination of IL6 with the risk of further development in colorectal cancer.

TNF- $\alpha$

TNF- $\alpha$ is another pleiotropic cytokine that has been found to be implicated in the pathophysiology of the IBD in the response to infection and tissue injury. However, there is no evidence that TNF- $\alpha$ concentration is likely to be associated with colorectal cancer risk (Table
1). A surrogate marker for TNF- $\alpha$, soluble tumor necrosis factor receptor 2 (sTNFR-2), that is more stable in stored frozen samples and less influenced by diurnal variation was significantly associated with increased risk of CRC in women in the Nurses' Health Study [52].

\section{Other markers}

Serum amyloid A (SAA) is a nonspecific inflammatory marker produced in the liver in response to infection, trauma, and other inflammatory states and has been hypothesized to be a more sensitive marker of inflammation over CRP for certain diseases [55]. However, pre-diagnostic concentrations of SAA were not associated with CRC in the Women's Health Initiative Observational Study. Macrophage inhibitory cytokine 1 (MIC-1) is another novel inflammatory biomarker, which was positively associated with colorectal cancer risk in the Nurses' Health Study and the Health Professionals Follow-up Study [56]. Fibrinogen concentrations were positively associated with the risk of colon cancer in another prospective study in the USA, but white blood cell count, von Willebrand factor, factor VIII, and albumin did not yield statistically significant associations [57]. However, white blood cell count was associated with an increased risk of colon cancer in a Swedish and a Korean prospective study $[58,59]$.

\section{Mediterranean diet and colorectal cancer}

In 2010, UNESCO recognized the MedD as an "intangible cultural heritage of Italy, Greece, Spain and Morocco" for multiple reasons, such as the preservation of local biodiversity and a variety of health benefits starting from a reduction of CRC risk and the percentage of deaths caused by cardiovascular accidents [60-62]. The MedD is characterized by a high consumption of fruits, vegetables, and complex carbohydrates; low consumption of fish and meat; and a daily glass of red wine. In the MedD, the main source of fat is olive oil [63]. 
Prevention of CRC has important public health implications. Many studies have demonstrated that fibers and phytochemicals included in the MedD have a strong chemopreventive role in the onset of CRC [64].

\section{Olive oil}

Olive oil is a central compound in the MedD and is the main source of dietary fat. The MedD is distinguishable from other healthy dietary models for its high-fat content [61]. Many experimental studies outline the biological and molecular mechanism by which each component of olive oil could realize multiple health benefits $[65,66]$. The consumption of olive oil exerts a protective effect in reducing risk for CRC many other types of cancer, including prostatic and breast. This property has been referred to by its content of monounsaturated fats, mainly oleic acid $[67,68]$.

However, olive oil is a functional and complex food that contains several minor bioactive compounds, including tocopherols, squalene, alcohols, and many polyphenols such as oleuropein, hydroxytyrosol, and tyrosol, which represent approximately $80 \%$ of olive oil's phenolic content. Although the mechanisms involved remain uncertain, pre-clinical studies have attributed many chemopreventive effects to the components of olive oil mostly because they interfere with the initiation, promotion, and progression of cancerogenesis pathways [65,69-73] (Table 1).

\section{Red grapes and resveratrol}

Resveratrol is a phenolic substance found mostly on the outer skin of red grapes and other food products (e.g., berries and nuts). Resveratrol is mostly present in red wine in the MedD. However, its red wine content varies considerably in terms of quality and climate for red grape species [74]. Pleiotropic pharmacological characteristics of resveratrol include platelet aggregation repression and eicosanoid synthesis. It enhances the preservation of reactive oxygen and flogistic events against damage, which gives rise to cardiovascular protection and anticancer properties.[75].

Although it is difficult to ascertain the cause and effect mechanism in in vivo settings, resveratrol has been shown to affect a number of molecular targets based on cancer type, resveratrol formulation, stage of disease, and dose and duration of resveratrol. It is being increasingly recognized that the combinatorial approaches of resveratrol and other natural agents are likely useful in advanced stages of cancers because deregulation of multiple pathways affects cancer cell growth and oncogenic signalling [76].

\section{Tomatoes and lycopene}

According to Smith, "tomato pills cure all your ills" [58]. In fact, tomatoes, which are central protagonists in the MedD, have several beneficial effects, especially in the prevention of cardiovascular diseases, osteoporosis, and cancer. A reduction of risk for CRC of $>20 \%$ has been linked to the daily intake of fruits and vegetables, including tomatoes [77]. The extraordinary action of tomatoes has been attributed to their elevated content of carotenoids, primarily b-carotene and lycopene [78].

Lycopene is synthesized by plants and confers the color red not only to tomatoes but also to red oranges and apricots. After the consumption of tomatoes, the concentration of lycopene in plasma depends on several biological mechanisms. In fact, lycopene is modified during the digestive process, thus decreasing its bioavailability. To facilitate lycopene absorption, it is better to introduce tomatoes in combination with lipids, such as occurs in sauces or juices [79].

\section{SCREENING GUIDELINES}

It is worth noting that almost all of the recommendations are reasonable, with the exception that barium enemas are lowered to just $48 \%$ for low levels of sensitivity [77]. Additionally, the regularity of stool DNA analysis is questionable; as such a test is quite new. However, all the 
remaining screening approaches are validated by all the societies as suitable screening methods. Colonoscopy even if its effects in a reliable randomized controlled study on the decline incidence and mortality of CRC have not been demonstrated. The logical question would therefore be: was it effective? The newest study data assessing the prevalence of CRC in both males and females have shown a decline in CRC incidence as well as in CRC mortality in both genders related to the start of screening programs[80].

\section{SCREENING OPTIONS \\ FS and colonoscopy}

In the 1980s and 1990s, fecal occult blood and sigmoidoscopy were the most used screening techniques. Later on, however, most colonoscopy screening of CRC was performed. Colonoscopy is a gold standard tool for high sensitivity and specificity screening. This test can detect and resect precarious lesions and neoplasms throughout the large intestines and is the ultimate evaluation for other diagnostic tests. With recent statistics showing a perforation rate less than $1 / 1000$ most typically related to a polypectomy rather than the act itself it is reasonably safe. In certain circumstances, colonoscopy requires full preparation of the bowel and sedation [34]. Colonoscopy is commonly available but not accessible or cheap for the general public, which means that it is difficult to adjust its use to screening programs. In future studies with cohorts and numerous cases, cancer mortality was predicted to be $68 \%$ to $88 \%$ lower among individuals with colonoscopy screening compared to those not[35]. A meta-analysis of observational studies revealed that regardless of a $68 \%$ lower overall mortality, limited advantage from colonoscopy was seen with respect to cancer in the proximal colon $[81,82]$. Another study revealed that there was a $29 \%$ reduction in overall CRC mortality, a $47 \%$ reduction in mortality from distal $\mathrm{CRC}$, and no reduction in mortality from proximal CRC. This study showed that colonoscopy significantly reduces mortality from CRC, but the benefit is not even across different areas of the colon. This may be due to several factors that affect the quality of the event as such (e.g. training level and experience of the gastroenterologist, incomplete colonoscopy, inadequate bowel preparation, or technical issues with polyp removal in the proximal colon) [83].

\section{gFOBT}

gFOBT spot the presence of blood in feces through a chemical reaction reliant upon the peroxidase activity of heme. It is a low-cost, simple, and extensively available test. A revolutionary study that evaluated the fecal occult blood test randomized 46551 participants 50 to 80 years of age to screen for CRC on a once-a-year basis, every two years, or to a control group. They concluded that yearly fecal occult blood testing with rehydration of the samples cut the13-year increasing mortality from CRC by $33 \%$ [84].

\section{FIT}

FIT is a new type of guaiac-based FOBT. It is an antibody to human globin that does not cross-react with dietary meats. Therefore, no prerequisite foods avoidance with peroxidase activity. Upper gastrointestinal globin is degraded readily by digestive proteolytic enzymes so FIT carefully measures the colonic blood. The FIT sampling technique is simple and easy to collect with fewer fecal samples required compared to FOBT.

\section{CTC}

CTC or virtual colonoscopy is a rapid, noninvasive radiographical imaging test that involves no less risky sedation than colonoscopy. Moreover, it brings the advantage of additional intestinal evaluation. In addition to that, it conveys the advantage of extracolonic assessment. However, a patient must take the same preparation as for colonoscopy so CTC is not very pleasant in addition to the same discomfort during the procedure. In addition, other risks of CTC include allergy 
to contrast, radiation exposure and the requirement for colonoscopy if positive findings are considered [85-87].

\section{cfDNA and ctDNA as diagnostic tool}

In 2011, the Italian group evaluated cfDNA's capacity to differentiate between healthy patients with RC (plasma samples collected after negative colonoscopy). The baseline cfDNA levels were considerably greater in RC patients compared to healthy patients by methods of quantitative PCR (using Alu 115, Alu 147, and $\beta$-globin gene) [88].

A Chinese group also observed a higher concentration of cfDNA in RC than in healthy individuals, where mutated KRAS and methylated MGMT were not detected. Moreover, the ratio of 400-/100-bp DNA fragments (an index of cfDNA integrity) was higher in RC patients than in healthy controls, in which cfDNA is considered to originate mainly from an apoptotic process of normal cells [89].

Shalaby et al. underlined the ability to differentiate benign and malignant rectal cancer by the MGMT and ERCC1 methylation conditions. 43 benign and 50 malignant rectal tumors were examined for the blood and tissue. They observed a significantly higher frequency of MGMT and ERCC1 methylation in RC patients than in cases with benign tumors, both in tissue and blood samples (sensitivity around 60\% and specificity of $93-95 \%$ for each gene on plasma). The combination of MGMT and ERCC1 methylation reached a specificity for differentiation between benign and malignant rectum tumors of $100 \%$ in blood samples, with a sensitivity of $32 \%$ [90].

\section{Colonoscopy}

Over the last decade, cases of colorectal cancer have grown due to early diagnosis of premalignant asymptomatic tumors. Early detection leads to reduced malignancy, early detection of the tumor, which leads to improved forecasts with long-term outcomes. Largely male, younger and high body mass indexes are diagnosed with screening (BMI). It is revealed in the study that symptomatic patients had more than twice the risk of having a malignant disease which contributes to the fact that the contribution of colonoscopy is essential for early detection. Early detection effect the TNM stage, invasiveness of tumor, nodal spread and distant metastasis in surgical pathology. So these factors also affect the long-term outcome of treatment. Early detection has a tremendous effect on prolonging longevity, improving quality of life and reducing health care cost through detection of colon cancer in early stages. Initially, colonoscopy was done in all patients for the assessment of colorectal cancer.

\section{Serum carcinoembryonic antigen (CEA)}

Serum carcinoembryonic antigen (CEA) is used as an important tumor marker for colon cancer demonstrated 45 years ago. Its sensitivity and specificity have been extensively researched and show some weaknesses which lead to rejection to use CEA as a potential screening tool. CEA is mostly used for the follow-up to monitor the risk of local and distant recurrence after surgical resection of the tumor. CEA is considered as the value of choice to monitor and it sufficiently correlates with colorectal tumor activity. Consistent elevation of CEA is an alarming sign for the recurrence of colorectal cancer. The prognostic value of CEA is preoperatively controversial and a long subject of debate, however, several studies provided evidence that preoperative CEA levels can be indicative of the risk of postoperative recurrence. $5 \mathrm{ng} / \mathrm{L}$ to $100 \mathrm{ng} / \mathrm{l}$ is the cut-off value for CEA for the population at a risk.

\section{CT and Other tests}

$\mathrm{CT}$ is performed in all patients either early or late stage while MRI is performed in all late stages to confirm metastasis. If the patient had confirmed diagnosis then all baseline tests (CBC, LFTs, RFTs, and PFTs), biochemical test, coagulation test, related imaging examination, and assessment of the risk of surgery before 
operation. Tumor markers (i.e. CA-125 etc.) were performed to confirm the diagnosis.

\section{Monoclonal antibodies in cancer immunotherapy}

Cancer vaccines try to impact the immune system cells by generating an attack against the cancer cells. Cancer vaccines are designed to induce tumorspecific or tumor-reactive immunoreactivity in vivo. Peptide vaccines comprised of immunogenic epitopes usually formed of tumor-specific or cancer antigens are the most prevalent type [91].

Vaccines are usually administered with other adjuncts called adjuvants to increase the effectiveness of the immune system. Dendritic cells (DCs) are used as natural adjuvants because of their ability to initiate and support immune responses. DCs vaccination is performed by two different approaches, direct targeting of antigens to DC receptors or ex vivo production of antigen-loaded DCs. In the case of DNA vaccines, plasmids containing cDNAs encoding tumor antigens are administered to the patient so that the patient begins to express these antigens and provides immunity and $\mathrm{T}$ cell response against them [92].

\section{Adoptive cell therapy}

Adoptive cell therapy (ACT) is the process of administering immunologically active cells to the patient for treatment and prevention of the formation of the disease list shown in Table 1. ACT involves the collection of immune cells from the patient's peripheral blood or the tumor itself, the isolation of cells, the ex vivo replication of tumor-specific immune cells, and the re-infusion of activated $\mathrm{T}$ cells to the patient $[93,94]$.

$\mathrm{T}$ cells used for this purpose are tumor-infiltrating lymphocytes (TILs), T cells engineered to express a cancer-specific $\mathrm{T}$ cell receptor (TCR) expression, and $\mathrm{T}$ cells for regulated chimeric antigen receptor (CAR) expression, which combines the extracellular portion of the antibody with the signalling mechanism of the TCR. In addition, DCs, which are antigen-presenting cells and highly effective in inducing T-cell immunity, are also used in this approach $[92,95]$.

\section{Monoclonal Antibodies}

As a result of the entry of a foreign substance into the body, B-lymphocytes become active and antibody production takes place in recognition of this foreign substance (antigen). Antibodies recognize the epitope regions on the antigen. If an antibody is produced against a single epitope instead of an entire epitope, this antibody is called a monoclonal antibody (mAb) $[96,97]$.

\section{Cytokines}

Cytokines are chemicals produced by some immune system cells. Cytokines play an important role in the production and activity of immune system cells and blood cells. Although there are many different types, the most commonly used are interleukins, interferons, and granulocytemacrophage colony-stimulating factor (GMCSF) [98].

Table 1: Commonly used adoptive cell therapy in colorectal cancer.

\begin{tabular}{|l|l|l|c|}
\hline Generic Name & \multicolumn{1}{|c|}{ Type } & Target & FDA approval \\
\hline Rituximab & Chimeric & CD20 & 1997 \\
\hline Transtuzumab & Humanized & HER2 & 1998 \\
\hline Aletuzumab & Humanized & CD52 & 2001 \\
\hline Bevacizumab & Humanized & VEGF & 2004 \\
\hline Panitumumab & Human & EGFR & 2006 \\
\hline Ofatumumab & Human & CD20 & 2009 \\
\hline Denosumab & Human & RANKL & 2010 \\
\hline Ipilimumab & Human & CTLA-4 & 2011 \\
\hline Pertuzumab & Humanized & HER2 & 2012 \\
\hline Obinutuzumab & Humanized & CD20 & 2013 \\
\hline Nivolumab & Human & PD-1 & 2014 \\
\hline Pembrolizumab & Humanized & PD-1 & 2014 \\
\hline Ramucirumab & Humanized & VEGF & 2014 \\
\hline Daratumumab & Human & CD38 & 2015 \\
\hline Necitumumab & Human & EGFR & 2015 \\
\hline Avelumab & Human & PD-L1 & 2017 \\
\hline Durvalumab & Human & PD-L1 & 2017 \\
\hline
\end{tabular}

\section{"Watch and Wait" Non-operative Experience:}

The 'watch and wait' strategy for patients achieving a neo-adjuvant $\mathrm{cCR}$ is conceptually appealing, as first described by Brazilian researchers [99]. In an updated dataset, 361 cT2-4N0/N+ patients with CRT-treated rectal tumors were reported in 
the Habr Gama Group. Repeat endoscopic evaluation of patients was performed 8 weeks after CRT, and patients with mucosal abnormalities or positive biopsies were deemed to have an incomplete response and proceeded to surgical resection. Those found to have a cCR underwent rigorous monitoring and surveillance. Ninety-nine patients with a prolonged cCR greater than 1 year were managed without surgery. Following a 5- year follow-up period, 13 patients experienced recurrences: 5 were endorectal, 7 were distant, and 1 was both. All patients with isolated endorectal recurrences were salvaged successfully. The 5-year OS and DFS were high at $93 \%$ and $85 \%$, respectively [100].

A prospective Dutch study of a "watch and wait" approach was previously published [101]. An update of these results with a larger patient population and longer follow-up (median 41 months) was recently published. Between 2004 and 2014, 100 patients with cT1-3 N0-2 who received CRT had a cCR (61 patients) or near cCR (39 patients) and underwent organ preservation. Evaluation of response involved DRE, endoscopy, and MRI. Patients with a cCR underwent watch and wait, while near cCR patients were given the option TME or reassessment at 3 months. Endoscopy and MRIs were performed every 3 months during the first year and every 6 months thereafter. Fifteen patients experienced a local recurrence (12 luminal, 3 nodal), all occurring within 25 months and salvageable. Five patients developed metastases and 5 patients died. Three-year overall survival was high at $96.6 \%$ (95\% confidence interval $(\mathrm{CI})=89.9$ to $98.9 \%)$, and colostomy-free survival was $94.8 \%$ $(95 \% \mathrm{CI}=88.0$ to $97.8 \%)$ [102]

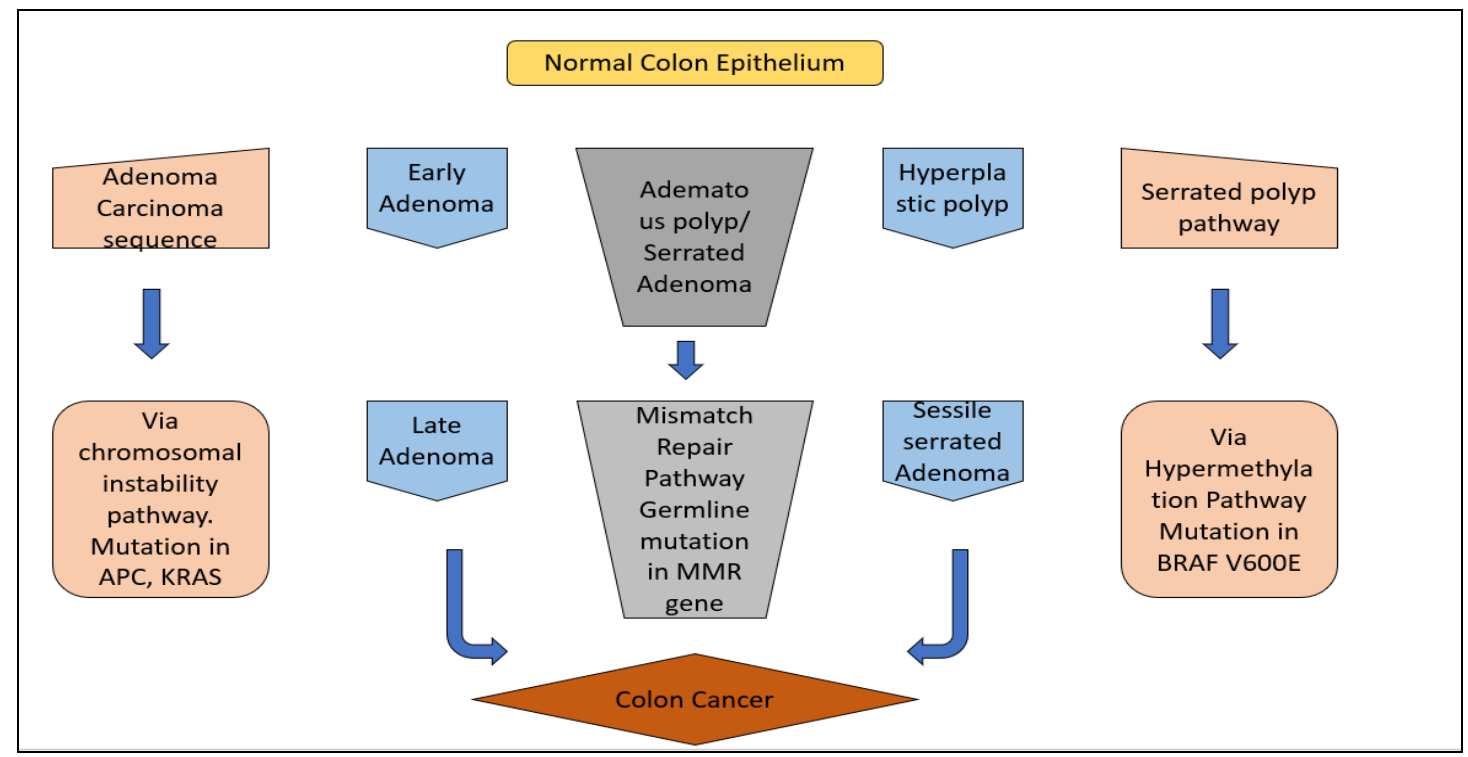

\section{CONCLUSION}

Inflammation affects every facet of tumor development and might also affect the efficacy of cancer therapies. Antiinflammatory drugs can reduce CRC risk and clinical trials should indicate the therapeutic efficacy of anti-inflammatory biologics, such as anti-TNF, anti-IL-6, antiIL-1, and inhibitors of NF-B and STAT3. Importantly, anti-inflammatory drugs target myeloid and lymphoid cells, which do not carry oncogenic mutations and, therefore, do not undergo rapid evolution and selection. This is a highly attractive feature of anti-inflammation therapies they might avoid the rapid development of resistance that occurs to drugs that target cancer cells. Anti-inflammatory reagents that can be used to prevent and treat CRC and CAC might be combined with conventional therapies, such as chemo- or radiotherapy, to increase their efficacy.

Acknowledgement: None 


\section{Conflict of Interest: None}

\section{REFERENCES}

1. DeSantis CE, Lin CC, Mariotto AB, Siegel RL, Stein KD, Kramer JL, et al. Cancer treatment and survivorship statistics, 2014. CA. Cancer J Clin. 2014.

2. Van Cutsem E, Cervantes A, Adam R, Sobrero A, Van Krieken JH, Aderka D, et al. ESMO consensus guidelines for the management of patients with metastatic colorectal cancer. Ann Oncol 2016;27(8): 1386-422. [PubMed: 27380959].

3. Bufill JA. Colorectal cancer: evidence for distinct genetic categories based on proximal or distal tumor location. Ann Intern Med 1990;113(10):779-88. [PubMed: 2240880].

4. Gervaz P, Bucher P, Morel P. Two colonstwo cancers: paradigm shift and clinical implications. J Surg Oncol 2004;88(4):2616. [PubMed: 15565587].

5. Iacopetta B Are there two sides to colorectal cancer? Int J Cancer 2002;101(5):403-8. [PubMed: 12216066].

6. Hemminki K, Santi I, Weires M, Thomsen $\mathrm{H}$, Sundquist J, Bermejo JL. Tumor location and patient characteristics of colon and rectal adenocarcinomas in relation to survival and TNM classes. BMC Cancer 2010;10:688. [PubMed: 21176147].

7. Hill MA. Embryology gastrointestinal tract development. 2016.

8. Sadler TW. Langman's medical embryology. 2014.

9. Guinney J, Dienstmann R, Wang X, de Reynies A, Schlicker A, Soneson C, et al. The consensus molecular subtypes of colorectal cancer. Nat Med 2015;21(11): 1350-6. [PubMed: 26457759].

10. Gao Z, Guo B, Gao R, Zhu Q, Qin H. Microbiota disbiosis is associated with colorectal cancer. Front Microbiol 2015;6:20. [PubMed: 25699023].

11. Kohoutova D, Smajs D, Moravkova P, Cyrany J, Moravkova M, Forstlova M, et al. Escherichia coli strains of phylogenetic group B2 and D and bacteriocin production are associated with advanced colorectal neoplasia. BMC Infect Dis 2014;14:733. [PubMed: 25540872].

12. Zhang Y, Hoffmeister M, Weck MN, Chang-Claude J, Brenner H. Helicobacter pylori infection and colorectal cancer risk: evidence from a large population-based case-control study in Germany. Am J Epidemiol 2012;175(5):441-50. [PubMed: 22294430].

13. Dejea CM, Wick EC, Hechenbleikner EM, White JR, Mark Welch JL, Rossetti BJ, et al. Microbiota organization is a distinct feature of proximal colorectal cancers. Proc Natl Acad Sci USA 2014;111(51):18321-6. [PubMed: 25489084].

14. Flemer B, Lynch DB, Brown JM, Jeffery IB, Ryan FJ, Claesson MJ, et al. Tumourassociated and non-tumour-associated microbiota in colorectal cancer. Gut 2017;66(4): 633-43. [PubMed: 26992426].

15. Shen H, Yang J, Huang Q, Jiang MJ, Tan $\mathrm{YN}, \mathrm{Fu} \mathrm{JF}$, et al. Different treatment strategies and molecular features between right-sided and left-sided colon cancers. World J Gastroenterol 2015;21(21):6470-8. [PubMed: 26074686].

16. Missiaglia E, Jacobs B, D’Ario G, Di Narzo AF, Soneson C, Budinska E, et al. Distal and proximal colon cancers differ in terms of molecular, pathological, and clinical features. Ann Oncol 2014;25(10):19952001. [PubMed: 25057166].

17. Lan YT, Jen-Kou L, Lin CH, Yang SH, Lin $\mathrm{CC}$, Wang HS, et al. Mutations in the RAS and PI3K pathways are associated with metastatic location in colorectal cancers. J Surg Oncol 2015; 111(7):905-10. [PubMed: 25920435].

18. Yamauchi M, Morikawa T, Kuchiba A, Imamura Y, Qian ZR, Nishihara R, et al. Assessment of colorectal cancer molecular features along bowel subsites challenges the conception of distinct dichotomy of proximal versus distal colorectum. Gut 2012;61(6): 847-54. [PubMed: 22427238].

19. Mouradov D, Sloggett C, Jorissen RN, Love CG, Li S, Burgess AW, et al. Colorectal cancer cell lines are representative models of the main molecular subtypes of primary cancer. Cancer Res 2014;74(12):3238-47. [PubMed: 24755471].

20. Rowan A, Halford S, Gaasenbeek M, Kemp Z, Sieber O, Volikos E, et al. Refining molecular analysis in the pathways of colorectal carcinogenesis. Clin Gastroenterol Hepatol 2005;3(11): 1115-23. [PubMed: 16271343].

21. Lee MS, McGuffey EJ, Morris JS, Manyam $\mathrm{G}$, Baladandayuthapani $\mathrm{V}$, Wei $\mathrm{W}$, et al. Association of $\mathrm{CpG}$ island methylator 
phenotype and EREG/AREG methylation and expression in colorectal cancer. $\mathrm{Br} \mathrm{J}$ Cancer 2016;114(12): 1352-61. [PubMed: 27272216].

22. Mayer B, Zoller M, Singer T, Magosch S, Joka M, Werner J. Targeted therapy using trastuzumab will overcome chemotherapeutic failure in liver metastasis of colorectal cancer. Eur Surg Res 2015.

23. Lee MSASM, Morris J, Jiang Z-Q, Manyam GC, Menter D, Broom BM, et al. Association of primary (1_) site and molecular features with progression-free survival (PFS) and overall survival (OS) of metastatic colorectal cancer (mCRC) after anti-epidermal growth factor receptor ( $\alpha$ EGFR) therapy. J Clin Oncol 2016;34.

24. Bendardaf R, Buhmeida A, Hilska M, Laato M, Syrjanen S, Syrjanen K, et al. VEGF-1 expression in colorectal cancer is associated with disease localization, stage, and longterm disease-specific survival. Anticancer Res 2008;28(6B):3865-70. [PubMed: 19192642].

25. Nasir A, Kaiser HE, Boulware D, Hakam A, Zhao H, Yeatman T, et al. Cyclooxygenase2 expression in right- and left-sided colon cancer: a rationale for optimization of cyclooxygenase-2 inhibitor therapy. Clin Colorectal Cancer 2004; 3(4):243-7. [PubMed: 15025797].

26. World Cancer Research Fund/American Institute for Cancer Research. Continuous Update Project Expert Report 2018. Diet, nutrition, physical activity and colorectal cancer. Available online: https://www.wcrf.org/dietandcancer. Last access: July 4, 2019.

27. Schwingshackl L, Schwedhelm C, Galbete $\mathrm{C}$, et al. Adherence to Mediterranean Diet and Risk of Cancer: An Updated Systematic Review and Meta-Analysis. Nutrients 2017; 9. doi: 10.3390/nu9101063.

28. Newcomb PA, Norfleet RG, Storer BE, Surawicz TS, MarcusPM (1992) Screening sigmoidoscopy and colorectal cancer mortality. J Natl Cancer Inst 84:1572-1575

29. Sellers TA, Kushi LH, Potter JDet al (1992) Effect of family history, body fat distribution, and reproductive factors on the risk of postmenopausal breast cancer. $\mathrm{N}$ Engl J Med 326:1323-1329.

30. Jorgensen OD, Kronborg O, Fenger C (2002) A randomized study of screening for colorectal cancer using faecal occult blood testing: results after 13 years and seven biennial screening rounds. Gut 50:29-32.

31. Kronborg O, Fenger C, Olsen J, Jorgensen OD, Sondergaard O(1996) Randomised study of screening for colorectal cancer with faecal-occult-blood test. Lancet 348:14671471.

32. Hardcastle JD, Chamberlain JO, Robinson MHE et al (1996) Randomized controlled trial of faecal-occult-blood screening for colorectal cancer. Lancet 348:1472-1477.

33. Mandel JS, Bond JH, Church TR et al (1993) Reducing mortality from colorectal cancer by screening for fecal occult blood.N Engl J Med 328:1365-1371.

34. NCI (2013) Colorectal cancer screening (PDQ_). National Cancer Institute, Rockville, MD. http://www.cancer.gov/cancertopics/pdq/scr eening/colorectal/HealthProfessional. Accessed 11Mar 2013

35. NCI (2013) Colorectal cancer prevention (PDQ_). National Cancer Institute, Rockville, MD. http://www.cancer.gov/cancertopics/pdq/pre vention/colorectal/HealthProfessional/page2 \#Section_995. Accessed 15 Feb 2013.

36. Kutluk MT, Ataş E. Gastrointestinal cancers in children. In: Yalcin S, Philip P, editors. Textbook of gastrointestinal oncology. Cham: Springer; 2019.

37. Pezhouh MK, Montgomery EA. Pathological evaluation, classification, and staging of colorectal cancers. In: Yalcin S, Philip P, editors. Textbook of gastrointestinal oncology. Cham: Springer; 2019.

38. Kumamoto K, Ishida H. Clinical Management of Hereditary Colorectal Cancer. In: Ishida $\mathrm{H}$, Koda $\mathrm{K}$, editors. Recent advances in the treatment of colorectal cancer. Singapore: Springer; 2019. A recent review of classification, molecular, and clinical features of each of the two most common hereditary colorectal cancer syndromes.

39. Stern B, McGarrity T, Baker M. Correction to: incorporating colorectal cancer genetic risk assessment into gastroenterology practice. Curr Treat Options Gastroenterol. 2019;17:702-15.

40. Yılmaz A, Mirili C, Bilici M, Tekin SB. Colorectal cancer in lynch syndrome associated with PMS2 and MSH6 
mutations. Int J Color Dis. 2020;35(2):3513.

41. Aihara H, Kumar N, Thompson CC. Diagnosis, surveillance, and treatment strategies for familial adenomatous polyposis: rationale and update. Eur $\mathrm{J}$ Gastroenterol Hepatol. 2014;26(3):255-62.

42. Cavallo D, Ballardini G, Ferrari A, Delconte G, Signoroni S, Sala P, et al. Wireless capsule endoscopy in adolescents with familial adenomatous polyposis. Tumori. 2016;102(1):40-4.

43. Jeon JY, Jeong DH, Park MG, Lee JW, Chu SH, Park JH, Lee MK, Sato K, Ligibel JA, Meyerhardt JA, Kim NK. Impact of diabetes on oncologic outcome of colorectal cancer patients: colon vs. rectal cancer. PLoS One. 2013;8(2):e55196. doi: 10.1371/journal. pone.0055196. Epub 2013 Feb 6. PMID: 23405123 ; PMCID: PMC3566217.

44. Song YM, Sung J, Ha M. Obesity and risk of cancer in postmenopausal Korean women. J Clin Oncol. 2008 Jul 10;26 (20): 3395-402. doi: 10.1200/JCO.2007.15.7867. PMID: 18612154.

45. Gabay C, Kushner I. Acute-phase proteins and other systemic re- sponses to inflammation. N Engl J Med. 1999;340(6): 448-54.

46. Mazlam MZ, Hodgson HJ. Why measure C reactive protein? Gut. 1994;35(1):5-7.

47. Kishimoto T, Akira S, Narazaki M, Taga T. Interleukin-6 family of cytokines and gp130. Blood. 1995;86(4):1243-54.

48. Naka T, Nishimoto N, Kishimoto T. The paradigm of IL-6: from basic science to medicine. Arthritis Res. 2002;4 Suppl 3:S233-42.

49. Becker C, Fantini MC, Wirtz S, Nikolaev A, Lehr HA, Galle PR, et al. IL-6 signaling promotes tumor growth in colorectal cancer. Cell Cycle. 2005;4(2):217-20.

50. Il'yasova D, Colbert LH, Harris TB, Newman AB, Bauer DC, Satterfield S, et al. Circulating levels of inflammatory markers and cancer risk in the health aging and body composition cohort. Cancer Epidemiol Biomarkers Prev. 2005;14(10):2413-8.

51. Heikkila K, Harris R, Lowe G, Rumley A, Yarnell J, Gallacher J, et al. Associations ofcirculating $\mathrm{C}$-reactive protein and interleukin- 6 with cancer risk: findings from two prospective cohorts and a metaanalysis. Cancer Causes Control. 2009;20 (1):15-26.
52. Chan AT, Ogino S, Giovannucci EL, Fuchs CS. Inflammatory markers are associated with risk of colorectal cancer and chemopreventive response to anti-inflammatory drugs. Gastroenterology. 2011;140(3):799808. quiz e11.

53. Ho GY, Wang T, Gunter MJ, Strickler HD, Cushman M, Kaplan RC, et al. Adipokines linking obesity with colorectal cancer risk in postmenopausal women. Cancer Res. 2012;72(12):3029-37.

54. Song M, Wu K, Ogino S, Fuchs CS, Giovannucci EL, Chan AT. A prospective study of plasma inflammatory markers and risk of colorectal cancer in men. $\mathrm{Br} \mathrm{J}$ Cancer. 2013;108(9):1891-8.

55. Gabay C, Kushner I. Acute-phase proteins and other systemic responses to inflammation. N Engl J Med. 1999;340 (6):448-54

56. Mehta RS, Song M, Bezawada N, Wu K, Garcia-Albeniz X, Morikawa T, et al. A prospective study of macrophage inhibitory cytokine-1 (MIC-1/GDF15) and risk of colorectal cancer. J Natl Cancer Inst. 2014; 106(4), dju016.

57. Prizment AE, Anderson KE, Visvanathan K, Folsom AR. Association of inflammatory markers with colorectal cancer incidence in the atherosclerosis risk in communities study. Cancer Epidemiol Biomarkers Prev. 2011;20(2):297-307.

58. Van Hemelrijck M, Holmberg L, Garmo H, Hammar N, Walldius G, Binda E, et al. Association between levels of C-reactive protein and leukocytes and cancer: three repeated measurements in the Swedish AMORIS study. Cancer Epidemiol Biomarkers Prev. 2011;20(3):428-37.

59. Lee YJ, Lee HR, Nam CM, Hwang UK, Jee SH. White blood cell count and the risk of colon cancer. Yonsei Med J. 2006;47(5): 646-56.

60. World Cancer Research Fund/American Institute for Cancer Research. Continuous update project report. Food, nutrition, physical activity, and the prevention of colorectal cancer. Available at: http://www.wcrf.org/int/ research-wefund/continuous-update-project-cup. Accessed July 10, 2017.

61. Trichopoulou A, Bamia C, Trichopoulos D. Anatomy of health effects of Mediterranean diet: Greek EPIC prospective cohort study. BMJ 2009;338:2337. 
62. Mattioli AV, Miloro C, Pennella S, Pedrazzi $\mathrm{P}$, Farinetti A. Adherence to Mediterranean diet and intake of antioxidants influence spontaneous conversion of atrial fibrillation. Nutr Metab Cardiovasc Dis 2011;23:11521.

63. Bach A, Serra-Majem L, Carrasco JL, Roman B, Ngo J, Bertomeu I, et al. The use of indexes evaluatin the adherence to the Mediterranean diet in epidemiological studies: a review. Public Health Nutr 2006; 9:132-46.

64. Couto E, Boffetta P, Lagiou P, Ferrari P, Buckland G, Overvad K, et al. Mediterranean dietary pattern and cancer risk in the EPIC cohort. Br J Cancer 2011;104: 1493-9.

65. Banks LD, Amoah P, Niaz MS, Washington MK, Adunyah SE, Ramesh A. Olive oil prevents benzo(a)pyrene [B(a)P]-induced colon carcinogenesis through altered $\mathrm{B}(\mathrm{a}) \mathrm{P}$ metabolism and decreased oxidative damage in Apc(Min) mouse model. J Nutr Biochem 2016;28:37-50.

66. Di Francesco A, Falconi A, Di Germanio C, Micioni Di Bonaventura MV, Costa A, Caramuta S, et al. Extra virgin olive oil upregulates $\mathrm{CB} 1$; tumor suppressor gene in human colon cancer cells and in rat colon via epigenetic mechanisms. J Nutr Biochem 2015;26:250-8.

67. Braakhuis AJ, Campion P, Bishop KS. Reducing breast cancer recurrence: The role of dietary polyphenolics. Nutrients 2016;6: 8-9.

68. Toteda G, Lupinacci S, Vizza D, Bonofiglio R, Perri E, Bonofiglio M, et al. High doses of hydroxytyrosol induce apoptosis in papillary and follicular thyroid cancer cells. J Endocrinol Invest 2016;40:153-72.

69. Perez-Jimenez F, Ruano J, Perez-Martinez P, Lopez-Segura F, Lopez- Miranda J. The influence of olive oil on human health: not a question of fat alone. Mol Nutr Food Res 2007;51:1199-208.

70. Casaburi I, Puoci F, Chimento A, Sirianni R, Ruggerio C, Avena P, et al. Po- tential of olive oil phenols as chemopreventive and therapeutic agents against cancer: a review of in vitro studies. Mol Nutr Food Res 2013;57:71-83.

71. Llor X, Pons E, Roca A, Alvarez M, Mane J, Fern?andez-Banares F, et al. The effects of fish oil, olive oil, oleic acid and linoleic acid on colorectal neoplastic processes. Clin Nutr 2003;22:71-9.

72. Corona G, Deiana M, Incani A, Vauzour D, Dessi MA, Spencer JP. Inhibition of p38/CREB phosphorylation and COX-2 expression by olive oil poly- phenols underlies their anti-proliferative effects. Biochem Biophys Res Commun 2007;362: 606-11.

73. Sun L, Luo C, Liu J. Hydroxytyrosol induces apoptosis in human colon cancer cells through ROS generation. Food Funct 2014;5:1909-14.

74. Bertelli AA. Wine, research and cardiovascular disease: instructions for use. Atherosclerosis 2007;195:242-7.

75. Kursvietiene L, Staneviciene I, Mongirdiene A, Bernatoniene J. Multiplicity of effects and health benefits of resveratrol. Medicina (Kaunas) 2016;52:148-55.

76. Singh CK, George J, Ahmad N. Resveratrol-based combinatorial strategies for cancer management. Ann N Y Acad Sci 2013;1290:113-21.

77. Franceschi S, Parpinel M, La Vecchia C, Favero A, Talamini R, Negri E. Role of different types of vegetables and fruit in the prevention of cancer of the colon, rectum, and breast. Epidemiology 1998;9:338-41.

78. McCullough ML, Giovannucci EL. Diet and cancer prevention. Oncogene 2004;23: 6349-64.

79. Failla ML, Chitchumronchokchai C, Ferruzzi MG, Goltz SR, Campbell WW. Unsaturated fatty acids promote bioaccessibility and basolateral secretion of carotenoids and a-tocopherol by Caco-2 cells. Food Funct 2014;5:1101-12.

80. Nishihara R, Wu K, Lochhead P, Morikawa $\mathrm{T}$, Liao X, Qian ZR,Inamura K, Kim SA, Kuchiba A, Yamauchi M, Imamura Y, WillettWC, Rosner BA, Fuchs CS, Giovannucci E, Ogino S, Chan AT.Longterm colorectal-cancer incidence and mortality after lower endoscopy. N Engl J Med 2013; 369: 1095-1105 [PMID: 24047059DOI: 10.1056/NEJMoa1301969].

81. Kahi CJ, Imperiale TF, Juliar BE, Rex DK. Effect of screening colonoscopy on colorectal cancer incidence and mortality. ClinGastroenterol Hepatol 2009; 7: 770775; quiz 711 [PMID:19268269 DOI: 10.1016/j.cgh.2008.12.030].

82. Manser CN, Bachmann LM, Brunner J, Hunold F, BauerfeindP, Marbet UA. 
Colonoscopy screening markedly reduces the occurrence of colon carcinomas and carcinoma-related death: a closed cohort study. Gastrointest Endosc 2012; 76: 110117 [PMID:22498179 DOI: 10.1016/j.gie.2012.02.040].

83. Mandel JS, Bond JH, Church TR, Snover DC, Bradley GM,Schuman LM, Ederer F. Reducing mortality from colorectal cancer by screening for fecal occult blood. Minnesota Colon Cancer Control Study. N Engl J Med 1993; 328: 1365-1371 [PMID:8474513 DOI: 10.1056/ NEJM199305133281901].

84. Kim DH, Pickhardt PJ, Taylor AJ, Leung WK, Winter TC,Hinshaw JL, Gopal DV, Reichelderfer M, Hsu RH, Pfau PR. CTcolonography versus colonoscopy for the detection of advanced neoplasia. N Engl $\mathbf{J}$ Med 2007; 357: 1403-1412 [PMID: 17914041DOI: 10.1056/NEJMoa070543].

85. Ziemlewicz TJ, Binkley N, Pickhardt PJ. Opportunistic Osteoporosis Screening: Addition of Quantitative CT Bone Mineral Density Evaluation to CT Colonography. J Am Coll Radiol 2015; 12: 1036-1041 [PMID: 26435117 DOI: 10.1016/j.jacr. 2015.04.018].

86. Burling D, Halligan S, Slater A, Noakes MJ, Taylor SA. Potentially serious adverse events at CT colonography in symptomatic patients: national survey of the United Kingdom. Radiology 2006;239: 464-471 [PMID: 16569789 DOI: 10.1148/radiol. 2392051101]

87. World Health Association. Mortality Database. Available online:https://www.who.int/healthinfo/globa 1_burden_disease/estimates/en/. Last access: July 4, 2019.

88. Agostini M, Pucciarelli S, Enzo MV, Del Bianco $\mathrm{P}$, Briarava $\mathrm{M}$, Bedin $\mathrm{C}$, et al. Circulating cell-free DNA: a promising marker of pathologic tumor response in rectal cancer patients receiving preoperative chemoradiotherapy. Ann Surg Oncol 2011;18:2461-8.

https://doi.org/10.1245/s10434-011-1638-y.

89. Sun W, Sun Y, Zhu M, Wang Z, Zhang H,

$\mathrm{Xin} Y$, et al. The role of plasma cell-free DNA detection in predicting preoperative chemoradiotherapy response in rectal cancer patients. Oncol Rep 2014;31:1466-72. https://doi.org/10.3892/or.2013. 2949.
90. Shalaby SM, El-Shal AS, Abdelaziz LA, Abd-Elbary E, Khairy MM. Promoter methylation and expression of DNA repair genes MGMT and ERCC1 in tissue and blood of rectal cancer patients. Gene 2018;644:66-73.

https://doi.org/10.1016/j.gene. 2017.10.056.

91. Seledtsov VI, Goncharov AG, Seledtsova GV (2015) Multiple- purpose immunotherapy for cancer. Biomed Pharmacother 76:24-29.

92. Farkona S, Diamandis EP, Blasutig IM (2016) Cancer immuno- therapy: the beginning of the end of cancer? BMC Med. 14.

93. Mayor M, Yang N, Sterman D et al (2016) Immunotherapy for non-small cell lung cancer: current concepts and clinical trials. Eur J Cardio-Thoracic Surg 49:1324-1333.

94. Neves H, Kwok HF (2015) Recent advances in the field of anti- cancer immunotherapy. BBA Clin 3:280-288.

95. Rini B (2014) Future approaches in immunotherapy. Semin Oncol 41:S30-S40. https://doi.org/10.1053/j.seminoncol.2014. 09.005 .

96. Bean ES (2000) Polyclonal Antibodies. In: Howard GC, Bethell DR (eds) Methods in antibody production and characterization. CRS Press, Taylor and Francis Group, New York, pp 31-50.

97. Kohler H (2000) Superantibodies synergy of innate and acquired immunity. Appl Biochem Biotechnol 83:1. https ://doi.org/ 10.1385/ABAB:83:1-3.

98. Rini B (2014) Future approaches in immunotherapy. Semin Oncol 41:S30-S40. https://doi.org/10.1053/j.seminoncol.2014. 09.005 .

99. Habr-Gama A, Perez RO, Nadalin W, Sabbaga J, Ribeiro U Jr, Silva e Sousa AH $\mathrm{Jr}$, et al. Operative versus nonoperative treatment for stage 0 distal rectal cancer following chemoradiation therapy: longterm results. Ann Surg. 2004;240(4):711-7; discussion 7-8. https://doi.org/10.1097/01. sla.0000141194.27992.32 The initial description of a watch and wait approach to management of rectal cancer.

100. Habr-Gama A, Perez RO, Proscurshim I, Campos FG, Nadalin W, Kiss D, et al. Patterns of failure and survival for nonoperative treatment of stage $\mathrm{c} 0$ distal rectal cancer following neoadjuvant chemoradiation therapy. J Gastrointest Surg. 
2006;10(10):1319-28; discussion 28-9. https://doi.org/10.1016/j.gassur.2006.09.005

101. Maas M, Beets-Tan RG, Lambregts DM, Lammering G, Nelemans PJ, Engelen SM, et al. Wait-and-see policy for clinical complete responders after chemoradiation for rectal cancer. J Clin Oncol. 2011; 29 (35):4633-40.

https://doi.org/10.1200/JCO.2011.37.7176.

102. Martens MH, Maas M, Heijnen LA, Lambregts DM, Leijtens JW, Stassen LP, et al. Long-term outcome of an organ preservation program after neoadjuvant treatment for rectal cancer. J Natl Cancer Inst. 2016;108(12). https://doi.org/10.1093/ jnci/djw171.

How to cite this article: Muhammad Ali, Yang Wang, Qi Zhang et.al. Different mechanism involvement in the formation of colorectal cancer; mega review. international journal of research and review. 2021; 8(9): 558-573. DOI: https://doi.org/10.52403/ijrr.20210971 